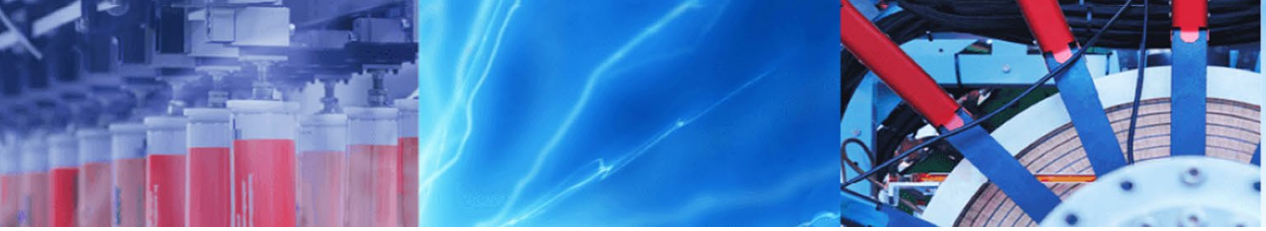

Research Article

\title{
Assessment of energy efficiency improvement methods in the residential sector through the development of economic experiments
}

\author{
Enrique Belenguer ${ }^{1}\left[\right.$ D $\cdot$ Nieves García ${ }^{1} \cdot$ Gerardo Sabater-Grande $^{2}$
}

(c) Springer Nature Switzerland AG 2019

\begin{abstract}
Energy efficiency has become one of the basic pillars with which to tackle climate change in the European Union where households accounted for $27 \%$ of final energy consumption in the year 2016 , the second largest sector after transport. This paper describes and draws conclusions from a series of economic experiments developed with the objective of analyzing the effectiveness of various methods for improving energy efficiency in the domestic sector. A distinction is made between informational methods, consisting in providing continuous information to the consumer about their energy performance, and economic methods which are based on an economic incentive calculated on the basis of the energy savings achieved with respect to a known reference. The experiments have been carried out both in the experimental economics laboratory and in the field (real dwellings) and have also made it possible to evaluate the applicability of experimental economics to this type of analysis, in which the economic behavior of the subjects is influenced by psychological and social aspects. Final results show that informational methods on their own are not sufficient to achieve and maintain substantial energy savings and should be accompanied by economic incentives.
\end{abstract}

Keywords Energy efficiency · Domestic sector · Experimental economics · Informational methods · Economic methods

\section{Introduction}

In the European Union, the improvement in energy efficiency has become one of the basic pillars to mitigate the emission of greenhouse gases and reduce dependence on energy from abroad. In 2016, approximately $27 \%$ of end-use energy was consumed in the residential sector [1], which shows the importance of proposing specific measures to encourage savings in this sector. In contrast to other sectors, energy consumption in households is characterized to a large extent by individual habits and behaviors that are not always rational.

Energy-saving policies have been mainly focused on the improvement in thermal enclosures, air conditioning systems (cooling and heating), lighting systems and household appliances. For instance, in the European Union, the principal Directives aim at regulating the minimum energy efficiency requirements for the construction or renovation of residential buildings, developing methods for calculating the energy label of buildings, stablishing the minimum requirements applicable to energy-using products and labeling and classifying energy-related products [2-5].

Even though different studies show significant savings thanks to the adoption of these policies $[1,6,7]$, their degree of effectiveness is in permanent discussion [8-10], partly because of the difficulty in developing a reliable measurement system, partly due to the difficulty of quantifying the influence of the human factor on energy consumption in the residential sector. Several studies

$\triangle$ Enrique Belenguer, efbeleng@uji.es|'Department of Industrial Systems Engineering, Universitat Jaume I, Avda. Sos Baynat, s/n, 12071 Castellón de la Plana, Spain. ${ }^{2}$ Department of Economics, Universitat Jaume I, Avda. Sos Baynat, s/n, 12071 Castellón de la Plana, Spain. 
[11-15] show differences among the theoretical calculations and the real results of the savings obtained with these improvements and attribute this discrepancy to the behavior of the inhabitants, which does not conform to the predictions. Therefore, knowledge of the individuals' behavior in the use of equipment consuming energy is fundamental to be able to establish the best policies of energetic saving in the house $[12,16]$.

In order to study the behavioral component of the energy consumption in the residential sector, householding consumption is divided in this article into two main categories: an inherent consumption, depending on the type and quantity of equipment installed, and a variable consumption, depending on the use of the equipment made by the inhabitants. Inherent consumption is related to the useful floor area of the house, the number of electrical appliances available, the number of household members and the climate zone in which the dwelling is located. To reduce the inherent consumption of a home, it is necessary to increase the energy efficiency of the equipment used, as well as the thermal envelopes of the dwellings themselves. Most of current energy efficiency policies aim at reducing this kind of consumption.

Variable consumption, on the other hand, is related to the lifestyle, consumption habits and values of the inhabitants. Two dwellings with the same inherent consumption can differ substantially in the variable consumption, which does not imply a greater degree of satisfaction in the house with increased consumption; it may simply be an indicator of inefficiency in the use of equipment [17]. An improvement in the energy efficiency of equipment also affects this component although main reductions can be reached through behavioral changes.

This article focuses on the analysis of reduction in the variable consumption component through the development of economic experiments related to three different methods: (1) methods based on information, (2) methods based on feedback and (3) methods based on economic incentives.

Information-based methods consist in providing users with information on how to use household equipment efficiently or on what should be taken into account in their acquisition [18]. By themselves they are not very effective, or they are only so in the short term. Information campaigns appear to be influential (reductions in around 3\%) but the persistence of the effect has been found to be very limited $[19,20]$.

One of the main issues that the users face when it comes to reducing their energy consumption in housing is the lack of information about their instantaneous and daily consumption of each piece of the equipment that they use. Of all the actions carried out over a month, the only information they receive is a value in $\mathrm{kWh}$ and its associated cost, which is the sum of the set of all the energy decisions taken over 30 days.

Feedback-based methods consist in providing the user with information about their consumption, as instantaneously as possible, so that they can change their behavior and see how this change is reflected in consumption. The types of feedback that are considered today are direct, indirect and disaggregated feedback.

Direct feedback consists in immediate feedback, obtained through a real-time meter. According to experiments, savings of between 5 and $15 \%$ are obtained. Information on the persistence of changes is variable, but in general it seems that, even with a certain downward trend, the effect is persistent. The most used systems are smart meters, which offer precise information about instantaneous consumption [21-24] and alarms. The latter do not show values but rather alert to certain events, such as excessive consumption or changes in the pricing period [25].

Indirect Feedback is feedback in which information has been processed in some way. It may consist in increasing the amount of information delivered with the bill, in the form of consumption histories, comparisons with other similar households or other means [20, 26-28]. In general, it is much less immediate than the previous one, and so smaller achievements are expected. The results of the experiments yield savings values of $0-10 \%$.

Disaggregated feedback consists in using an independent meter per appliance or group of them $[29,30]$. It is an expensive method and its installation is complex. A more feasible version is the use of software capable of distinguishing the consumption of each household appliance [31, 32]. Despite the technical difficulties involved in its application, it is clearly a method with a great potential.

European policies related to feedback consist basically in the replacement of traditional meters by electronic ones, with instantaneous measurement of the consumed energy. However, these meters are located out of view of users with an uncomfortable access to their instant measures (through the websites of the supply companies). Due to this, the informative and instantaneous feedback potential of these meters is partly wasted. In addition, electricity bills must contain historical consumption information: a type of indirect feedback that is inefficient in its results. Faruqi shows in [33] savings of approx $1.55-1.73 \%$ in an advanced metering infrastructure experiment involving 50,000 and 175,000 residential customers.

Finally, methods based on economic incentives consist in offering some kind of economic reward to the most efficient users. This reward would be added to the savings obtained thanks to the decrease in consumption, which in most cases is small. The feed-in-tariff concept is described in [34]. It consists in establishing an economic reward 
relative to the $\mathrm{kWh}$ saved. This concept is inspired by the system of the same name used in many countries of the European Union, including Spain, to promote renewable energies.

Boardmand proposes [35] to give each citizen a card with a certain number of tons of $\mathrm{CO}_{2}$. Every time a citizen buys electricity, gas, gasoline or any other type of energy source, this is subtracted from the card. When the card is finished, the owner may continue buying but at a more expensive price; likewise, the person who has excess amounts of $\mathrm{CO}_{2}$ can sell them. A similar idea is suggested in [36].

Economic incentives are widely used today in energy efficiency policies, and are considered to have a positive impact on savings [37,38], but are currently focused exclusively on improving the energy efficiency of buildings and appliances.

In this paper three experiments will be described, the first one being a laboratory experiment and the remaining two, field experiments. The general objective is to study different methods of reducing the consumption in housing based on varying the habits of its inhabitants.

Throughout the experiments, the premises and methodology of experimental economics have been respected. Experimental economics has been used in the field of energy for approximately the last 40 years. Some reviews of field experiments related to electrical energy following the bases of experimental economics can be found in $[33,39,40]$. Additionally, Frederiks et al. [41] highlighted the utility of applying key principles from psychology and behavioral economics in order to explain consumer decision making on household energy saving. In this vein, Hahn and Metcalfe [42] argue that the use of experiments can be very useful to understand how to change energy consumption decisions of consumers. Following this line, Lunn and Choisdealbha [43] use examples from recent research on energy efficiency decision making to state that laboratory experiments are often not only complementary to field experiments, but "also necessary to interpreting field results, and that such research can have direct policy implications." They conclude that laboratory experiments can be the best tool to provide evidence for policy makers.

\section{Methodology}

\subsection{General conditions of the experiments}

The main aim of the first experiment was to test, in a simple laboratory environment, the compared efficiency among diverse informative methods in order to determine, in later field experiments, the most effective ones.
The second experiment was designed to evaluate in the real world the applicability of one of the best-performing methods in Experiment No. 1: the use of a smart meter. For the experiment, a smart meter with an app for smartphone or tablet was installed in a series of houses in the province of Castellón (Spain), whereby the users could consult their data about the instant consumption, their consumption history, the hourly price of energy, the value of their next bill and others. This meter only took measures of the electricity consumption of the house.

The third economic experiment consisted in studying the changes in behavior achieved by economically remunerating the savings obtained. To this end, a group of volunteers was recruited and offered an economic reward in exchange for a certain decrease in their electricity consumption, measured in relation to their own consumption in the same months of the previous year. In order for the participants to have a reference as to whether they were achieving the objectives established in the experiments, they were sent weekly information on their performance.

\subsection{Description of Experiment No. 1. laboratory}

In this experiment, a virtual house was simulated in the laboratory and the energy performance of the experimental subjects in it was recorded. According to the Experimental Economics Laboratory policy, participants were selected from students of the different faculties and schools of the Universitat Jaume I de Castellón. Most of them lived in their own homes with their parents. Before the beginning of each session, participants were given written and spoken instructions and any doubts that they might have were solved. Subjects were divided into several groups and each group was informed with different types of feedback (treatments). The virtual household consisted of three members (father, mother and son/daughter), and was composed of a dining room, a kitchen, two bedrooms and a bathroom. Some of the house equipment used electrical energy while the other (heating and hot water) ran on gas.

For each appliance, a particular utility function was defined considering a standard use by a standard family. Utility is a function that measures the satisfaction obtained by a consumer when he or she enjoys a certain number of goods (see Fig. 1). For example, in the case of a washing machine, the utility is defined considering for the standard family (three members) an optimum use of 4 cycles per week and a maximum use of 14 cycles per week. The optimum point represents the greatest value of satisfaction with respect to the energy consumption.

The quantification is carried out in the form of money, and measures how much a person would be willing to pay to receive a service or buy a product. The more vital a good 


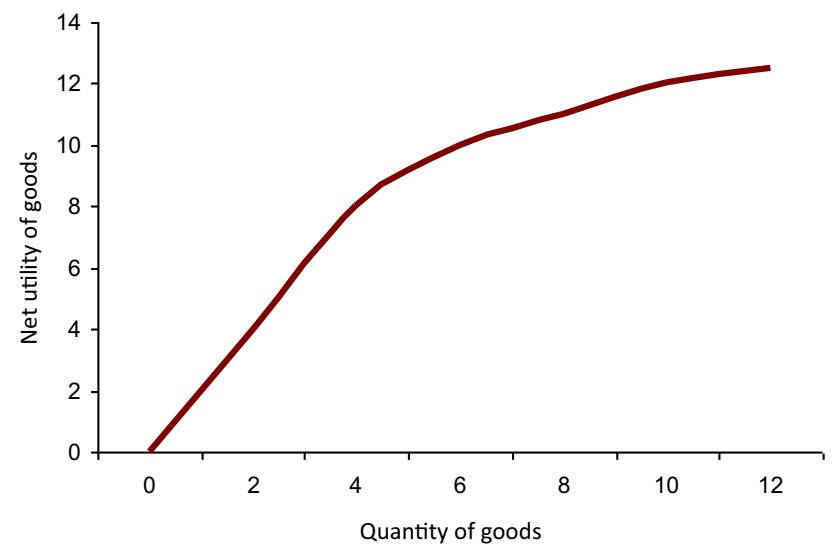

Fig. 1 Utility function

is, the greater its usefulness will be. Likewise, the greater the amount of a good, the lower the utility of the next unit will be. The function, as shown in Fig. 1, is always increasing but tends to saturation in a given number of units of the good.

The screen shown in Fig. 2 was designed for the simulation of the house. In it, the experimental subjects had the possibility to use the different appliances, heating, DHW and lighting during different hours and with different load and temperature cycles, number of uses, etc.

Together with each piece of equipment, the utility obtained by the particular use was showed. This value varied by changing the conditions of use of the equipment, and was shown equally to the participants of all treatments. The final aim of the subjects was to maximize their benefit or surplus, understood as the utility obtained by the use minus the energy consumed to obtain it, both given in euros as shown in Eq. (1). To maximize the surplus, each participant had to use the appliances taking into account his/her comfort (utility) and the estimated consumption of energy. The total utility was always shown to the participants while information regarding energy consumption was shown depending on the treatment.

SURPLUS $(€)=$ UTILITY $(€)-$ CONSUMPTION $(€)$

The experimental subjects manipulated the environment and used the equipment over several periods, which represented either a typical summer day or a winter day. The sequence, which consisted of 18 periods altogether, alternated 3 days of summer with 3 days of winter. The main difference between the two types of day was the use of heating. It is important to point out that, although the simulation cannot be considered entirely realistic, the behavior of the participants was completely rational and no abnormal use of the appliances was reported.

Once the subjects had considered that they had made all the necessary decisions for the day, they clicked on the "next" button, after which they were shown a simplified electricity bill, in $c €$, corresponding to the month represented by the immediately preceding day. The bill (see

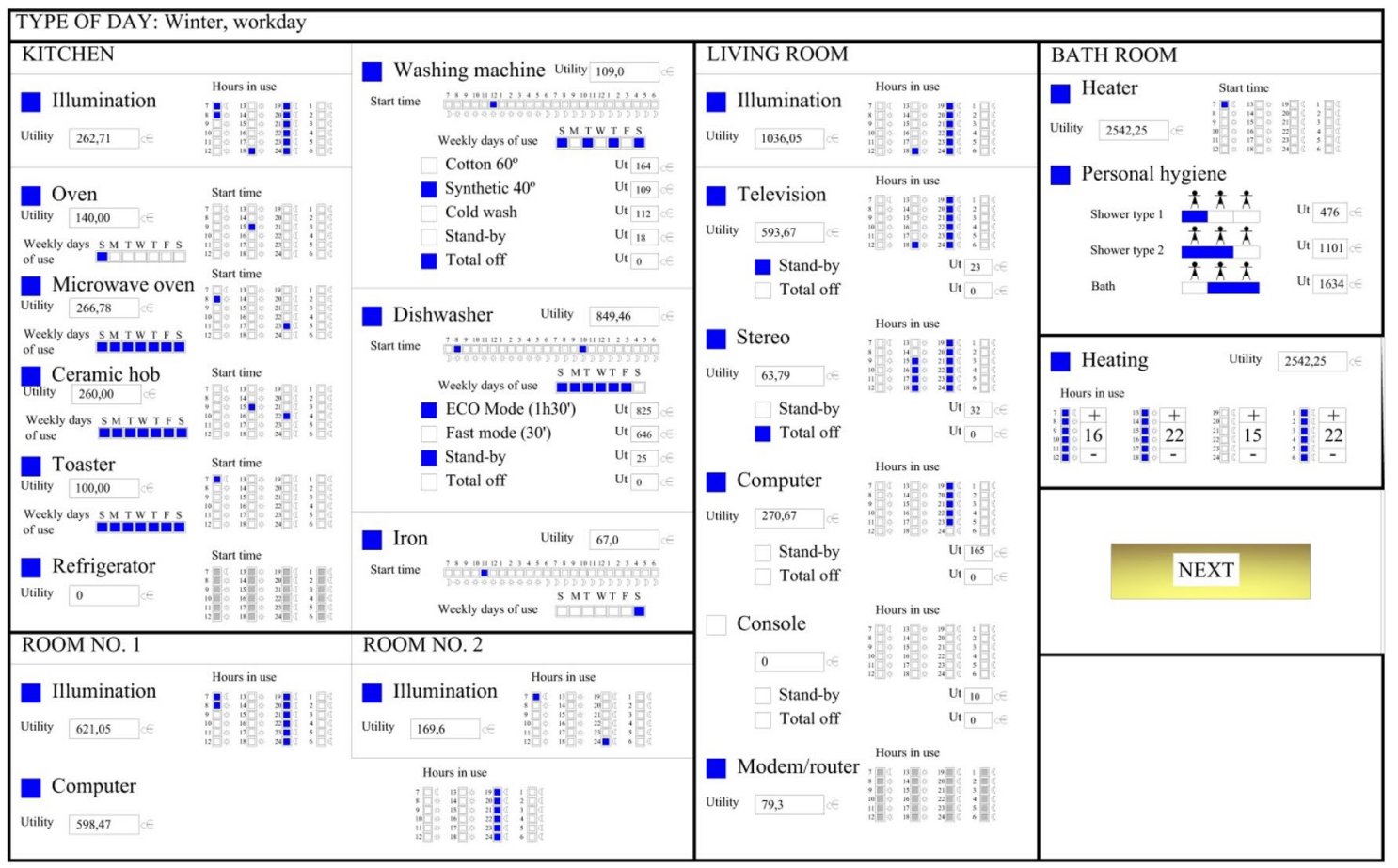

Fig. 2 Main programming screen 
Fig. 3) was calculated by multiplying by 30 the consumption on the day represented, and also included the total profit obtained by the subject, calculated in the same way. Gas and electricity bills were shown separately, as was the consumption history of the previous "months."

In this experiment, five different treatments were tested. In all of them, participants could see the screen and bill shown in Figs. 2 and 3.

In the Basic Treatment (TO), the only information received by the subjects about their monthly behavior was that appearing on the programming screen (Fig. 2) and that shown on the bill in Fig. 3.

In the Tips Treatment ( $T 1)$, the participants were also shown a series of tips for energy saving, which were repeated in each cycle, prior to the programming screen and the bill.

In the Meter Treatment (T2), participants could see, beside the programming screen, a smart meter showing their total instantaneous consumption in $\mathrm{kWh}$ and its corresponding cost in Euros. The bill does not vary with respect to the other treatments.

In the Disaggregated Meter Treatment (T3), subjects had five independent smart meters, which showed the instantaneous disaggregated consumption of the following groups of equipment: lighting, kitchen (oven, microwave oven and toaster), gas (heating and DHW), entertainment (TV, stereo and computers) and others (dishwasher, washing machine, iron and heater). Again, the bill continued to be the one shown in Fig. 3.

Finally, in the Ranking Treatment (T4), the only variation with respect to $T 0$ is that, along with the bill, comparative information on the consumption of the rest of the group was also shown. This particular case was repeated in two different sessions, with different experimental subjects, to increase the number of independent observations.

Altogether, 173 subjects participated in the sessions, 30 in each session except $T 2$, in which they were reduced to 23 . The experiments lasted between 90 and $120 \mathrm{~min}$, depending on the treatment. Subsequently, the subjects were paid an amount of money proportional to the benefits obtained according to their performance. Participants received an average amount of 20 Euros.

\subsection{Description of Experiment No. 2. information without incentives}

In this experiment, 71 experimental subjects were divided into two groups, Group I, made up of 22 people, and Group II, consisting of 46 people. Smart meters were installed in Group I's houses together with an energy metering app in their smartphones. Regarding Group II, they were asked for permission to access the website of their energy supply company, in order to check their consumption data. The purpose of this second group was to have data on the natural variation of consumption from one period to another in the absence of feedback.

Selected houses were located in the city of Castellón and surroundings in the east cost of Spain with a Mediterranean climate (mild winters and warm summers). The main criteria for the selection was to get the maximum similarity considering the characteristics of the houses, the appliances and the number of inhabitants. Most of the participants were standard families (working parents with

Fig. 3 Simplified bill

Billing period number..................... 4

ELECTRICITY BILL

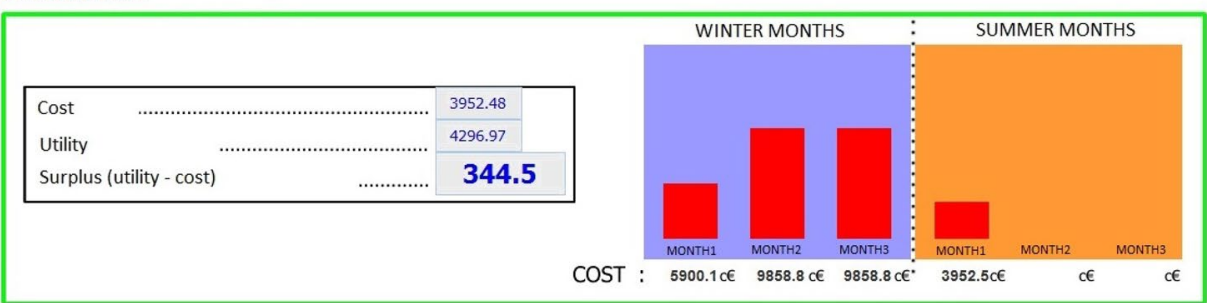

GAS BILL

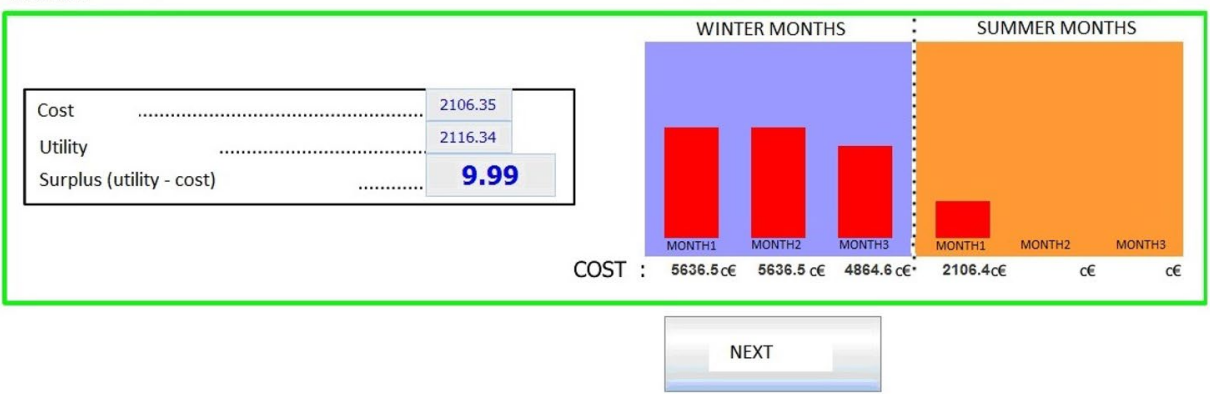

SN Applied Sciences 
one or two children). The socioeconomic characteristics of both groups are shown in Table 1.

All of the houses used heating and domestic hot water systems while the use of air conditioning was not relevant. Main energy carriers for heating and hot water systems are electricity and gas though in this experiment just electric energy consumptions are considered. Figure 4 shows the percentage rates for each domestic energy kind of consumption in the Spanish Mediterranean zone.

Figures 5 and 6 show two screenshots of the app distributed to Group I. Figure 5 is the initial screen of the application, and shows the total instantaneous consumption of the housing in Watts. This screen is refreshed every $3 \mathrm{~s}$. Pressing the first button on the menu to the right of Fig. 5 shows Fig. 6 . This screen shows a history of instantaneous consumption during the current day, with the possibility of expanding any of its parts. The remaining submenus include other information, such as an estimate of the bill for different types of contract, a calculation of the

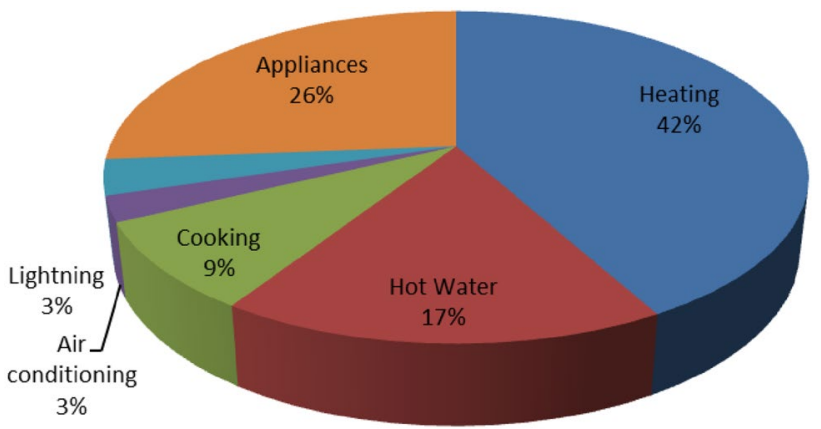

Fig. 4 Household energy consumptions for the Spanish Mediterranean zone

most advisable power to be contracted or a study on the consumption of the house.

Neither group benefited from any economic incentive, except for what they would presumably obtain in the form

Table 1 Socioeconomic characteristics of the groups belonging to Experiment No. 2

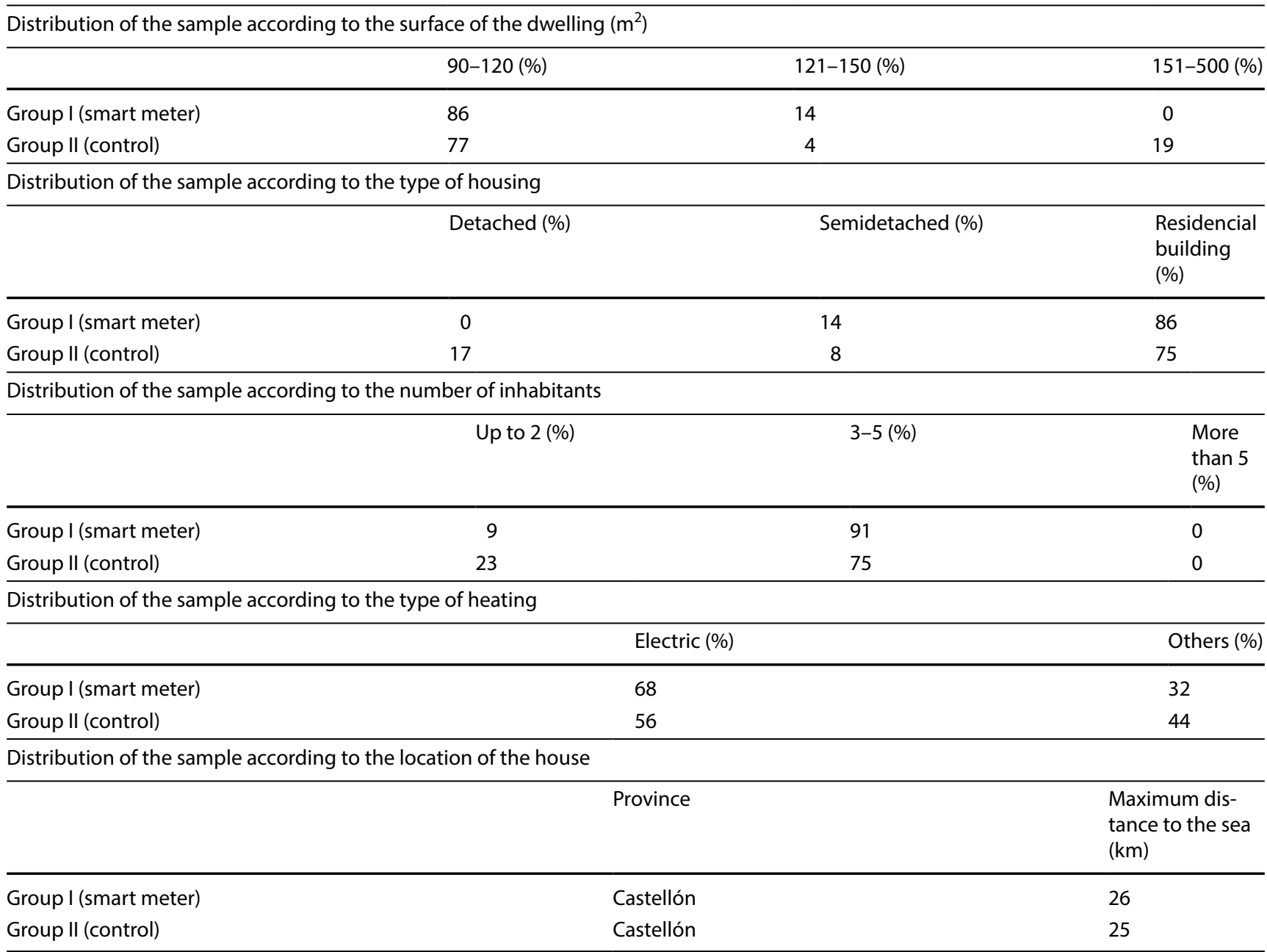


Fig. 5 OnMeter initial screen

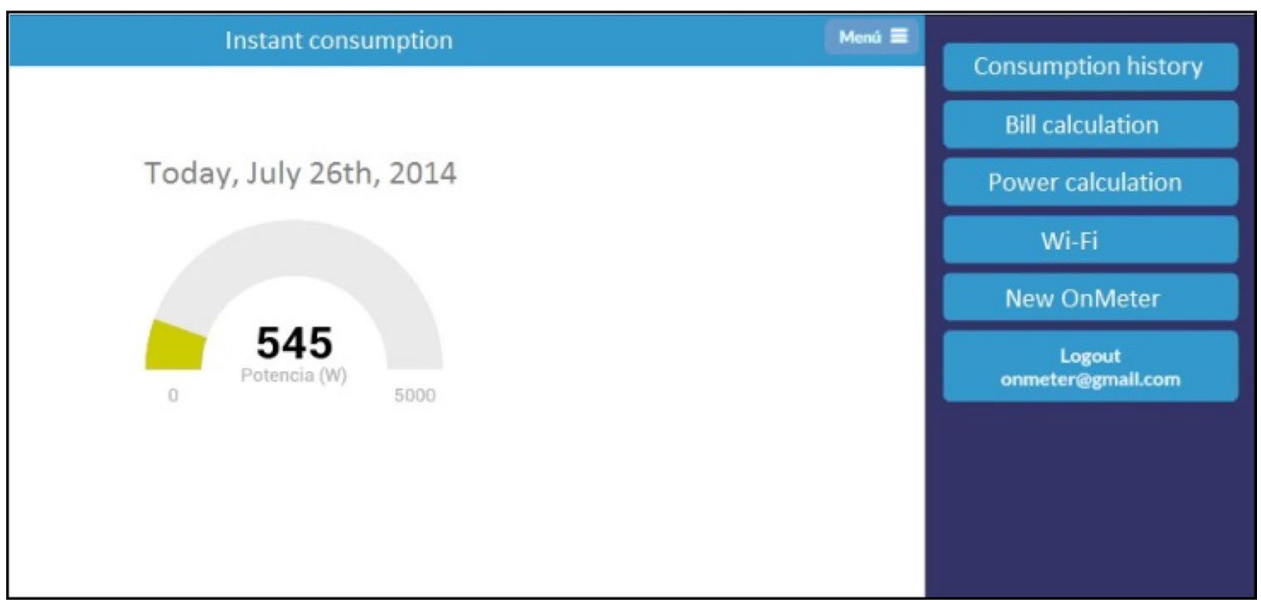

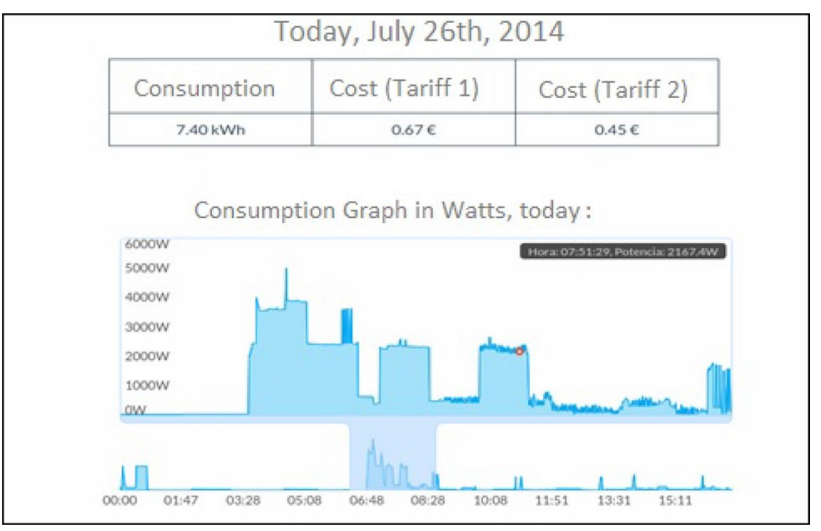

Fig. 6 Consumption history

of a reduction in the electric bill due to the decrease in consumption.

Consumption data were taken from both groups during the month prior to the distribution of the computer application, in order to have a reference of consumption in the absence of feedback. Once the application was installed to the subjects in Group I, data for 3 different periods of the year, each with a duration of approximately 1 month, were taken.

At the end of the experiment, participants were asked to fill out a survey about their participation in the experiment. Their responses are shown in Table 2.

\subsection{Description of Experiment No. 3. influence of an economic incentive}

Seventy experimental subjects took part in this experiment. They were divided into three groups. The first group, called Group I or Payment Group, made up of 25 subjects, was offered an economic reward proportional to the savings obtained. The reward was linearly variable
Table 2 Final survey Experiment No. 2

Do you think the smart meter helps you save?

A little

0

Regular

$44.4 \%$

A lot

$33.3 \%$

I do not know

$22.3 \%$

Do you think it is important to reduce the use of energy in the home?

Essential

Important

Not important

0

Totally unnecesary

0

Do you consider your energy performance efficient in recent years?

A little

0

Regular

$55.6 \%$

A lot

$45.4 \%$

I do not know

0

Do you check your electricity bill when you receive it?

The cost

The cost and the consumption in kWh

The cost, the consumption and the consumption history

I do not check it

0

If you want to save energy, what is/are the reason(s)?

Personal economy

National economy

0

Depletion of energy sources

Climate change

Do you have any of these problems to achieve savings?

I do not know what to do to save

I cannot see the effects of the changes I make

I do not have any references about what is normal to spend, so I do not know if I save or waste

The changes I could make cost me more money than I save 
between $€ 0$ for negative or zero savings, up to $€ 100$ for savings of $10 \%$ or greater. The savings were to be achieved during the months of October, November and December 2016, and were calculated with respect to the consumption of the same months 1 year before, in 2015. The group received weekly information about its consumption of the current year and the previous year.

The second group, called Group II or Control Group, also consisted of 25 subjects. In this case no financial reward was offered, although the same weekly information was sent as for Group I. The purpose of this second group was to have a reference of what the change in consumption would have been in the absence of the economic incentive.
Finally, a third group, called Group 0 or Blind Group, was formed, consisting of 20 people to whom no information or access to any type of reward was offered. The purpose of this third group was to evaluate the possible influence of feedback in the behavior of Groups I and II.

The socioeconomic characteristics of the three groups are shown in Table 3.

In order for the Group I participants to have a reference as to whether they were achieving the objectives set out in the experiment, their weekly performance information was sent to them as a message to their smartphone (Figs. 7 and 8). However, since feedback of information is in itself an aid to energy saving, information was sent to groups I and II alike. In this way, the possible modification of the behavior due to feedback is not a variable to be taken into

Table 3 Socioeconomic characteristics of the groups belonging to Experiment No. 3

\begin{tabular}{|c|c|c|c|c|}
\hline \multicolumn{5}{|c|}{ Distribution of the sample according to the surface of the dwelling $\left(\mathrm{m}^{2}\right)$} \\
\hline & \multicolumn{2}{|l|}{$90-120(\%)$} & $121-150(\%)$ & $151-500(\%)$ \\
\hline Group I (control) & \multicolumn{2}{|l|}{68} & 8 & 24 \\
\hline Group II (payment) & \multicolumn{2}{|l|}{68} & 20 & 12 \\
\hline Group 0 (blind) & \multicolumn{2}{|l|}{53} & 26 & 21 \\
\hline \multicolumn{5}{|c|}{ Distribution of the sample according to the type of housing } \\
\hline & \multicolumn{2}{|l|}{ Detached (\%) } & Semidetached (\%) & $\begin{array}{l}\text { Residencial } \\
\text { building } \\
\text { (\%) }\end{array}$ \\
\hline Group I (control) & \multicolumn{2}{|l|}{16} & 12 & 72 \\
\hline Group II (payment) & \multicolumn{2}{|l|}{16} & 4 & 80 \\
\hline Group 0 (blind) & \multicolumn{2}{|l|}{16} & 10 & 74 \\
\hline \multicolumn{5}{|c|}{ Distribution of the sample according to the number of inhabitants } \\
\hline & \multicolumn{2}{|l|}{ Up to $2(\%)$} & $3-5(\%)$ & $\begin{array}{l}\text { More } \\
\text { than } 5 \\
(\%)\end{array}$ \\
\hline Group I (control) & \multicolumn{2}{|l|}{25} & 75 & 0 \\
\hline Group II (payment) & \multicolumn{2}{|l|}{24} & 68 & 8 \\
\hline Group 0 (blind) & \multicolumn{2}{|l|}{36} & 64 & 0 \\
\hline \multicolumn{5}{|c|}{ Distribution of the sample according to the type of heating } \\
\hline & \multicolumn{3}{|c|}{ Electric (\%) } & Others (\%) \\
\hline Group I (control) & \multicolumn{3}{|c|}{56} & 44 \\
\hline Group II (payment) & & 56 & & 44 \\
\hline Group 0 (blind) & & 47 & & 53 \\
\hline Distribution of the $s$ & cation of the hou & & & \\
\hline & & & & $\begin{array}{l}\text { Maximum dis- } \\
\text { tance to the sea } \\
(\mathrm{km})\end{array}$ \\
\hline Group I (control) & & lón & & 16 \\
\hline Group II (payment) & & lón & & 25 \\
\hline Group 0 (blind) & & lón/Valencia & & 26 \\
\hline
\end{tabular}


Fig. 7 Weekly information sent to the smartphones of Groups I and II. Weekly consumption
Your consumption this week (kWh)

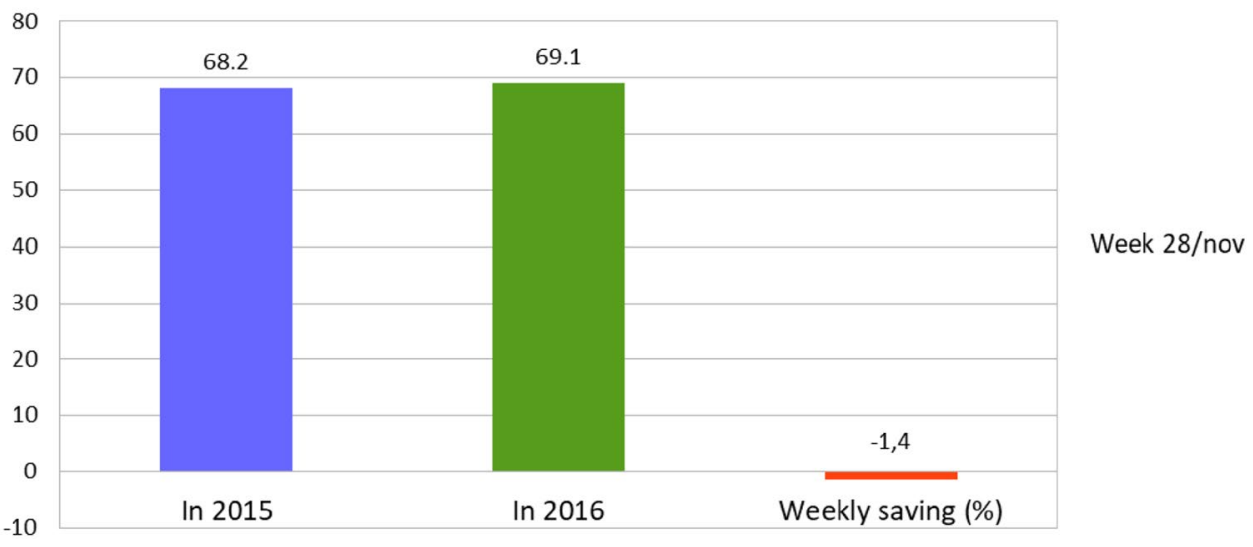

\section{Total consumptions}

to the smartphones of Groups I and II. Total consumption

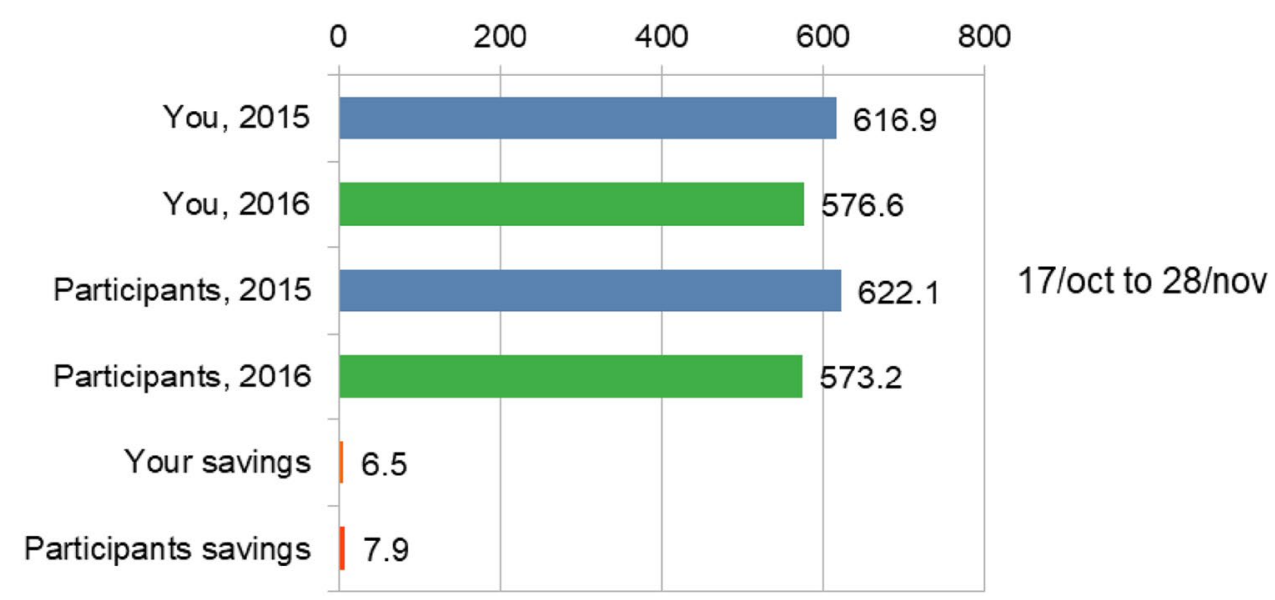

account, since it is the same for the 50 participants. Hence the need for a third blind group to evaluate the possible influence of feedback on groups I and II.

For the collection of consumption data for both Group I and Group II, all participants were asked for permission to access their data on the website of their supply company. Group 0 data were obtained from their electricity bills.

After the experiment was completed, the participants in Group I were given a survey about their participation in the experiment. Tables 4 and 5 summarize their responses.

\section{Results}

\subsection{Experiment No. 1}

The results of Experiment No. 1 are studied through two variables, Consumption and Surplus. Their descriptive statistics are shown in Table 6.
Table 4 Summary of resources used by Group I participants

\begin{tabular}{ll}
\hline Resource used & $\begin{array}{l}\text { Number of } \\
\text { times men- } \\
\text { tioned }\end{array}$ \\
\hline Turning off unnecessary lights & 10 \\
Optimizing the use of household appliances & 8 \\
Family Awareness & 6 \\
Unplugging unused devices & 4 \\
Optimizing the use of heating & 4 \\
Improvements in equipment & 2 \\
\hline
\end{tabular}

Figure 9 shows the average electricity consumption results for each treatment as a percentage of the optimal performance (100\%). Optimal behavior is defined as the most energy-efficient one without loss of comfort (maximization of surplus in Eq. (1)). The basic treatment, $T 0$, is shown as another point of comparison. 
Table 5 Summary of the utility of the weekly information sent by participants

\begin{tabular}{lll}
\hline Was it useful? & $\begin{array}{l}\text { Which graphic did you } \\
\text { watch the most? }\end{array}$ & $\begin{array}{l}\text { Number of } \\
\text { times men- } \\
\text { tioned }\end{array}$ \\
\hline Yes & & 15 \\
No & Weekly savings & 0 \\
& Total savings & 4 \\
& Website of the supply & 1 \\
& company & \\
& Comparisons & 1 \\
\hline
\end{tabular}

Table 6 Experiment No. 1 descriptive statistics

\begin{tabular}{llllll}
\hline Treatments & \multicolumn{2}{l}{$\begin{array}{l}\text { Electricity consumption } \\
(\mathrm{c} €)\end{array}$} & \multicolumn{2}{l}{$\begin{array}{l}\text { Electricity surplus } \\
(\mathrm{c} €)\end{array}$} \\
\cline { 2 - 3 } & Average & SD & & Average & SD \\
\hline$T 0$ & 3363.75 & 1059.77 & & 501.78 & 67.03 \\
$T 1$ & 3154.37 & 1464.79 & & 507.31 & 85.10 \\
$T 2$ & 3179.01 & 1180.91 & & 539.40 & 92.12 \\
$T 3$ & 3856.77 & 1420.80 & & 567.18 & 89.56 \\
$T 4$ & 3091.17 & 1185.52 & & 508.13 & 94.20
\end{tabular}

ELECTRICAL ENERGY CONSUMPTION related to an optimum

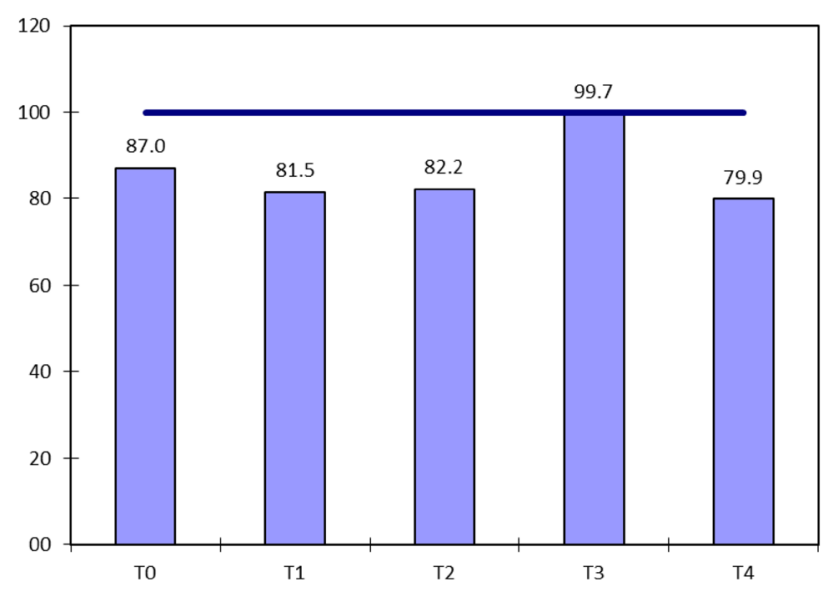

Fig. 9 Total electrical consumption of all treatments

In Fig. 9, it can be seen how all treatments show a lower consumption than the optimal one. In fact, it seems that all subjects showed an extremely thrifty behavior, because of the suggestion created by participation in an energy efficiency experiment, in the belief that large savings would lead to greater benefits. The behavior closest to the optimum is T3 (Disaggregated Meter).
ELECTRICAL ENERGY BENEFITS related to an optimum

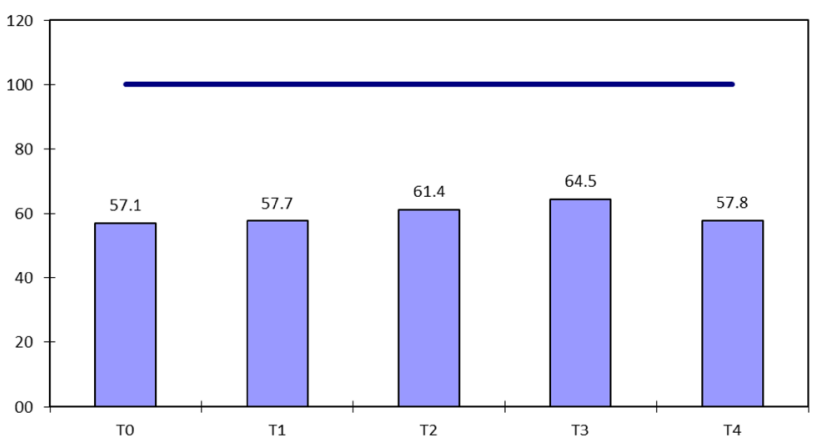

Fig. 10 Total electrical benefit of all treatments

When comparing the results shown in Fig. 9 , it can be seen that the most thrifty treatments are $T 1$ (Tips) and $T 4$ (Ranking). They are the two treatments with the greatest pressure relative to the savings, as well as the ones that had a poorer feedback system. The two groups have been characterized by the compulsion to save.

However, the behavior of the subjects is not explained exclusively by their energy consumption; it is also necessary to evaluate the level of personal gain obtained, since savings obtained from sacrifices in the quality of life are unlikely to be maintained over time.

The results related to the benefit (surplus in Eq. (1)) are shown in Fig. 10, also as a percentage of the optimum. In this case, the most successful treatments are $T 2$ (Meter) and T3 (Disaggregated Meter), which are the ones that benefit from a better feedback. Treatments $T 0$ (Basic), $T 1$ (Tips) and T4 (Ranking) sacrifice comfort to obtain their results. However, among them the Ranking performance is reasonably effective in achieving a profit when, at the same time, it is one of those that achieves the greatest savers in consumption.

Due to the way in which the utility function is constructed, profit maximization is equivalent to maintaining a moderate consumption while maintaining the satisfaction obtained with it. Since this experiment does not seek to reduce comfort but to minimize the expense necessary to maintain it, it is concluded that $T 2$ and $T 3$ are the most effective treatments.

\subsection{Experiment No. 2}

The behavior of the members of Group I was evaluated by comparing the average consumption of the participants of Groups I (Meter) and II (Control) during the month before the experiment (period 0 ), in which neither of them had access to their consumption. As a working hypothesis it is assumed that the relative difference between the mean 
values, in the absence of the smart meter and its app, would have remained stable over time. The data collection was divided into three sub-periods, the duration of which can be seen in Table 7 .

Once the average difference in consumption during period 0 is known, any deviation in the relative means of the two groups with respect to this period is interpreted as a result of the installation of the smart meter and its app. The comparison variable is, therefore, the increase in consumption with respect to period 0 . Its descriptive statistics are shown in Table 8.

The final results of the comparison between the two groups do not show an appreciable difference between them in any of the periods. Table 9 shows the average, the percent difference between the two groups, as well as the significance of the comparatives.

As can be seen in Table 9, the percentage differences between the samples are very small, ranging from -1 to $+1 \%$. In addition, they are not significant in any of the cases ( $p$ value always close to 1 ). The comparison was carried out through the Mann-Whitney test, since approximately half of the samples did not present a normal distribution.

\subsection{Experiment No. 3}

For the evaluation of the behavior of the members of Groups I and II, the performance of each group was compared with its equivalent period in the previous year. As a working hypothesis it is assumed that, in the absence of the economic incentive, the differences between 2015 and 2016 would be similar in the two groups, since both would have been subjected to the same environmental or other variations. The comparison variable used is the increase in consumption between 2015 and 2016. The variable is calculated so that negative increases represent savings in 2016 compared to 2015.

Between the years 2015 and 2016 there is a negative variation in consumption (a decrease in consumption) of Group I, while there is a variation of positive consumption (an increase in consumption) in both control Group II and in the Blind Group 0. Final results are summarized in Table 10, where it can be seen that the differences between

Table 7 Duration and seasonality of the four periods of the experiment

\begin{tabular}{ll}
\hline Period 0 & $\begin{array}{c}\text { One month, prior to the } \\
\text { distribution of the applica- } \\
\text { tion, fall }\end{array}$ \\
Period I & 1 month, fall \\
Period II & 1 month, winter \\
Period III & 1 month, summer \\
\hline
\end{tabular}

Table 8 Variable increase in consumption. Experiment No. 2 descriptive statistics

\begin{tabular}{lccc}
\hline $\begin{array}{l}\text { Increase between } \\
\text { periods }\end{array}$ & Mean (kWh) & SD $(\mathrm{kWh})$ & $N$ \\
\hline Group I & & & \\
I-0 & -46.99 & 101.37 & 22 \\
II-0 & -34.41 & 93.11 & 22 \\
III-0 & 15.47 & 141.48 & 22 \\
Group II & & & \\
I-0 & -24.79 & 49.07 & 46 \\
II-0 & -8.76 & 40.89 & 46 \\
III-0 & 27.55 & 82.08 & 46 \\
\hline
\end{tabular}

the two groups were significant ( $p$ value 0.013 and 0.09 , respectively). The differences between the blind and control groups were not significant ( $p$ value 0.594 ). Since a part of the sample does not present a normal distribution, the test used for the comparison was Mann-Whitney.

While Control Group II increased its consumption by $6.6 \%$ in the period studied, Group I, with a monetary incentive, reduced it by $7 \%$. Taking the control group as a reference for behavior in the absence of treatment, the reduction in consumption of Group I compared to what would have been expected behavior in 2016 is 14.6\%.

After the experiment was completed, all participants were asked to keep their accounts of the supply company

Table 9 Comparison of groups I and II during the 3 periods of the experiment

\begin{tabular}{ccccc}
\hline Period & $\begin{array}{l}\text { Average } \\
\text { consumption } \\
\text { (kWh) }\end{array}$ & Increase (kWh) & Savings (\%) & $\begin{array}{l}p \text { value } \\
\text { (Mann- } \\
\text { Whitney) }\end{array}$ \\
\hline Group I & & & & \\
0 & 280.91 & 24.42 & -8.69 & 0.550 \\
I & 305.33 & & & \\
Group II & & & & \\
0 & 296.55 & 24.79 & -8.36 & \\
I & 321.34 & & & \\
Group I & & & & \\
0 & 280.91 & 11.26 & -4.01 & \\
II & 292.17 & & & \\
Group II & & & & \\
0 & 296.55 & 8.76 & & \\
II & 305.30 & & & \\
Group I & & & & \\
0 & 280.91 & -22.94 & & \\
III & 257.97 & & & \\
Group II & & & & \\
0 & 296.55 & -27.55 & & \\
III & 269.00 & & & \\
\hline
\end{tabular}


Table 10 Comparison of results of groups 0 , I and II

\begin{tabular}{|c|c|c|c|c|c|c|}
\hline & \multirow{2}{*}{$\begin{array}{l}\text { Average consump- } \\
\text { tion (kWh) }\end{array}$} & \multirow{2}{*}{$\begin{array}{l}\text { Average } \\
\text { increase (kWh) }\end{array}$} & \multirow[t]{2}{*}{ Savings (\%) } & \multicolumn{3}{|c|}{$p$ value (Mann-Whitney) } \\
\hline & & & & I-II & $\mathrm{I}-0$ & II-0 \\
\hline \multicolumn{7}{|c|}{ Group I } \\
\hline 2015 & 583 & -41 & 7.03 & 0.013 & 0.009 & - \\
\hline 2016 & 542 & & & & & \\
\hline \multicolumn{7}{|c|}{ Group II } \\
\hline 2015 & 520.2 & 34.2 & -6.57 & 0.013 & - & 0.594 \\
\hline 2016 & 554.3 & & & & & \\
\hline \multicolumn{7}{|c|}{ Group 0} \\
\hline 2015 & 571 & 32.1 & -5.62 & - & 0.009 & 0.594 \\
\hline 2016 & 603 & & & & & \\
\hline
\end{tabular}

open to continue taking data and have the opportunity to check the persistence of the effect over the next 3 months.

The results are shown in Table 11. As can be seen, the significance of the Variation of Consumption variable continues to be significant. However, the difference between the groups has been reduced from 14.6 to $10.2 \%$.

\section{Discussion}

The results obtained in the experiments can be analyzed from a twofold perspective: a quantitative analysis reporting the savings obtained for each method and a qualitative analysis focusing on the fact that energy efficiency improvement in the domestic sector is a complex objective where the non-rational behavior of energy consumers plays a decisive role.

With respect to energy-saving results, Experiment No. 1 shows that providing the user with additional information than just the energy consumption value (treatments $T 1$, $T 2$ and T4) can yield savings up to $6 \%$ in the conditions of the experiment. As mentioned in Sect. 1, literature reports that information-based methods can provide savings around 3\% while direct-feedback methods result in savings between 5 and $15 \%$. This experiment shows that consumers are in general able to process complex information about their consumption and get relevant savings if they are motivated in somehow.

Contrary to the results obtained in some studies [21-24], in Experiment No. 2, the equality of the means of groups I and II throughout all periods, shows that the installation of smart meters along with their app does not imply any improvement in the energy performance of the participants. Although the results have not coincided with what was initially expected, the fact is that they clearly demonstrate that an informative tool; however, comprehensive, is not enough to guarantee a reduction in consumption by subscribers.

Experiment No. 3 results show that the potential savings that can be reached when providing an economic incentive related to energy savings are about $15 \%$ although evidently this result depends on the value of the reward. This value was obtained using an information tool that is far less sophisticated than the one designed for Experiment No. 2, which shows that, in fact, users already have a considerable knowledge of where energy is wasted in the home.

Apart from the energy-saving results, the three experiments can be considered an empiric demonstration of some of the behavioral tendencies explained in [13]. Experiment No. 1 shows, unexpectedly but very clearly, that the behavior of individuals is strongly influenced
Table 11 Results of the data collection after the end of the experiment

\begin{tabular}{|c|c|c|c|c|c|c|}
\hline \multicolumn{7}{|c|}{ Results of the period after the end of the experiment } \\
\hline & \multicolumn{2}{|c|}{ Consumption (kWh) } & \multicolumn{2}{|c|}{ Increase (kWh) } & \multirow[t]{2}{*}{ Savings (\%) } & \multirow{2}{*}{$\begin{array}{l}p \text { value } \\
\text { (Mann- } \\
\text { Whitney) }\end{array}$} \\
\hline & Average & Total & Average & Total & & \\
\hline \multicolumn{7}{|l|}{ Group I } \\
\hline Jan-Feb 2016 & 640 & $14,079.7$ & 20.7 & 455.2 & -3.23 & 0.039 \\
\hline Jan-Feb 2017 & 660.7 & $14,534.8$ & & & & \\
\hline \multicolumn{7}{|l|}{ Group II } \\
\hline Jan-Feb 2016 & 573.2 & $12,610.4$ & 79 & 1738.8 & -13.79 & \\
\hline Jan-Feb 2017 & 652.2 & $14,349.2$ & & & & \\
\hline
\end{tabular}


by the suggestion that they were expected to have an energy-efficient behavior. In the real world, people are not under so much pressure from the environment regarding their energy behavior but this experiment shows that a direct outside influence, such as advises of experts or the behavior of others, could be used to improve the energy use patterns of the people. It is important to note that the treatments analyzed in Experiment No. 1 are designed to optimize the way in which the equipment is used (i.e., increase utility in relation with energy consumption) and not sacrifice comfort. Although, it has not been proved in the experiment, it is reasonable to think that this approach is more likely to be persistent in time.

For its part, Experiment No. 2 shows that people have a strong resistance to change and tend to avoid tasks requiring some kind of effort and that are costly in the short term. Although providing the users with a powerful tool to follow their daily energy consumption and get significant savings, the subjects reduced very rapidly the use of the tool over time.

Regarding Experiment No. 3, it demonstrates the importance of motivation by some kind of reward or incentive. In this case an extrinsic motivation has been tested with very good results. It is important to emphasize (Table 7), the unanimous agreement about the importance of energy saving for the personal economy of the participants. One of the main problems of energy-saving measures at the residential level is that the improvements are only reflected in an electricity bill in which non-variable terms (power term, equipment rental and taxes) weigh more than the consumption. If one of the main incentives for users is the economic savings generated by energy efficiency measures, but any measure they take has almost no economic impact, the configuration of the electricity bill is a clear disincentive for energy saving.

It is significant that most of the resources used by the experimental subjects were behavioral (turning off lights and televisions that are not used, raising awareness, avoiding stand-by systems, optimizing the use of appliances) and did not imply a reduction in their quality of life (see summary in Table 9).

On the other hand, not all the participants obtained benefits; in fact, seven of them consumed more during the experiment than in the previous year. This demonstrates that a quality information tool is vital for a part of the population to be able to achieve significant savings.

\subsection{Political implications}

In the European Union, and under the current regulations, campaigns are being carried out to replace traditional meters with high-tech meters capable of providing instant consumption measures. At the same time, the distributors and marketers are making this information available to their customers, in the form of graphs and spreadsheets.

According to experts, the most effective energy efficiency measures in the European Union in the residential sector are those related to the energy labeling of both products and housing, as well as mandatory requirements for new or renovated buildings. However, and despite its apparent potential, smart-metering is considered to be one of the most ineffective measures.

Experiments 2 and 3 demonstrate that the problem does not lie in the amount of information provided to the user, but in the user's willingness to first access that information, and second, to use it in favor of energy efficiency.

Taking into account the financial outlay and the technical difficulties involved in replacing all meters and their implementation in a network that provides short-term measures to all its users, it is necessary to develop and apply some kind of incentives so that this policy reaches its maximum effectiveness.

\section{Conclusions}

In this paper three economic experiments, developed to examine the effectiveness of several energy efficiency methods in the domestic sector, have been presented. The main objective of the work was to analyze the economic behavior of energy consumers in order to help identify the best policies for energy savings in the sector. The experiments have been performed both in the laboratory and in real dwellings. Laboratory experiments allow a detailed, economic and fast analysis of individual behavior when the subjects receive different kinds of feedback. On the other hand, real dwelling experiments are more expensive and complex to develop but closer to realistic conditions. The right combination of both kinds of experiments allows testing a complete set of diverse energy-saving treatments with different characteristics.

The results show that in general people are able to process and use information and feedback applications (e.g., real-time consumption provided by a smart meter) in order to reduce their energy consumption. However, this measure is not enough in itself to reach substantial savings in an extended period of time. Environmental awareness and social pressure have also been proven to be methods that can lead to important savings but again these methods are not persistent in time. An important conclusion derived from the results of the first experiment is that that subjects' behavior is very dependent on external guidance and on the behavior of other people (social norms).

Information tools that are being developed by law (smart-metering of electrical energy, improvements in the information provided in the invoices, updated information 
on the website of the supplying companies), are based on the idea that a duly informed user will reduce his energy consumption. Experiment No. 2 shows that this premise is false. It is necessary to redesign energy policies to take into account the need to add an incentive, whether economic or otherwise, to the informative method.

In this sense, Experiment No. 3 demonstrates that the application of an economic incentive added to an information tool is proved to be the most effective method to achieve energy savings. In fact, the control group of Experiment No. 3 does not obtain any level of savings, and its behavior is very similar to that of the blind group, despite having the same information as the economically incentivized group. Most of the savings in this experiment have been obtained by behavioral changes, which demonstrates the potential that these contain. In addition, the potential is greater than assumed: there are subjects with consumption reduction capabilities that far exceed the barrier of $10 \%$. The effect is persistent in the short term: after the end of the experiment, the difference between the two groups with respect to the previous year is maintained. However, a reduction in $14.6-10.2 \%$ is observed over a period of 3 months.

\section{Compliance with ethical standards}

Conflict of interest On behalf of all the authors, the corresponding author states that there is no conflict of interest.

\section{References}

1. Tsemekidi Tzeiranaki S, Bertoldi P, Diluiso F, Castellazzi L, Economidou M, Labanca N, Ribeiro Serrenho T, Zangheri P (2019) Analysis of the EU residential energy consumption: trends and determinants. Energies 12:1065

2. European Parliament, Council of the European Union (2010) Directive 2010/31/EU of the European Parliament and of the Council of 19 May 2010 on the energy performance of buildings

3. European Parliament, Council of the European Union (2009) Directive 2009/125/EC of the European Parliament and of the Council of 21 October 2009 establishing a framework for the setting of ecodesign requirements for energy-related products

4. European Parliament, Council of the European Union (2010) Directive 2010/30/EU of the European Parliament and of the Council of 19 May 2010 on the indication by labelling and standard product information of the consumption of energy and other resources by energy-related products

5. European Parliament, Council of the European Union (2012) Directive 2012/27/EU of the European Parliament and of the Council of 25 October 2012 on energy efficiency

6. Aydin E, Brounen D (2019) The impact of policy on residential energy consumption. Energy 169:115-129

7. Bertoldi P, Mosconi R (2015) The impact of energy efficiency policies on energy consumption in the EU member states: a new approach based on energy policy indicators. EUR 27664 EN; Publications Office of the European Union, Luxembourg
8. Ruzzenenti F, Bertoldi P (2017) Energy conservation policies in the light of the energetics of evolution in complex systems and social practices in energy transitions. In: Labanca N (ed) Green energy and technology. Springer, Cham

9. Desilver D (2015) As American homes get bigger, energy efficiency gains are wiped out. Pew Research Center, Washington, D.C.

10. Rosenow J, Fawcett T, Eyre N, Oikonomou V (2016) Energy efficiency and the policy mix. Build Res Inf 44(5-6):562-574

11. Brenan TJ (2016) Behavioural economics and energy efficiency regulation. Reosurces for the future. Working paper

12. Bertoldi P, Serrenho T, Zangheri P (2016) Consumer feedback systems: How much energy saving will they deliver and for how long? In: ACEEE summer study on energy efficiency in buildings

13. Frederiks E, Stenner K, Hobman E (2015) Household energy use: applying behavioural economics to understand consumer decision-making and behaviour. Renew Sustain Energy Rev 41:1385-1394

14. Lopes MAR, Antunes $\mathrm{CH}$, Martins N (2012) Energy behaviours as promoters of energy efficiency: a 21st century review. Renew Sustain Energy Rev 16:4095-4104

15. Majcen D, Itard L, Visscher H (2013) Actual and theoretical gas consumption in Dutch dwellings: What causes the differences? Energy Policy 61:460-471

16. Aydin E, Kok N, Brounen D (2017) Energy efficiency and household behaviour: the rebound effect in the residential sector. RAND J Econ 48(3):749-782

17. Bagera S, Mundaca L (2017) Making 'Smart Meters' smarter? Insights from a behavioural economics pilot field experiment in Copenhagen, Denmark. Energy Res Soc Sci 28(2017):68-76

18. Delmas MA, Fischlein M, Asensio Ol (2013) Information strategies and energy conservation behavior: a meta-analysis of experimental studies from 1975 to 2012. Energy Policy 61:729-739

19. Darby S (2006) The effectiveness of feedback on energy consumption. Environmental Change Institute, University of Oxford, Oxford

20. Henryson J, Hakansson T, Pyrko J (2000) Energy efficiency in buildings through information: Swedish perspective. Energy Policy 28(2000):169-180

21. Alahmad MA, Wheeler PG, Schwer A, Eiden J, Brumbaugh A (2011) A comparative study of three feedback devices for residential real-time energy monitoring. IEEE Trans Ind Electron 59(4):2002-2013

22. Hydro One (2006) The impact of real-time feedback on residential electricity consumption: the hydro-one pilot. Study conducted by Professor Dean Mountain, McMaster Institute for Energy Studies \& De Groote School of Business. McMaster University Ontario

23. Karbo $P$, Larsen $T$ (2005) Use of online measurement data for electricity savings in Denmark. In: ECEEE 2005 summer study: panel 1. Strategies and integrated policies, pp 161-164

24. Wood G, Newborough M (2003) Dynamic energy-consumption indicators for domestic appliances: environment, behaviour and design. Energy Build 35:821-841

25. Faruqui $A$, Wood $L$ (2008) Quantifying the benefits of dynamic pricing in the mass market. Edison Electric Institute, Washington, D.C.

26. Egan C, Kempton W, Lord D, Payne C (1996) How customers interpret and use comparative graphics of their energy use. In: Proceedings of the 1996 ACEEE summer study on energy efficiency in buildings. Berkeley, CA, American Council for an Energy-Efficient Economy

27. McLennan Magasanik Associates Pty Ltd (2005) Showing comparative energy consumption information on customers' bills: report to Queensland Department of Energy 
28. Wilhite $H$, Ling $R$ (1995) Measured energy savings from a more informative energy bill. Energy Build 22:145-155

29. Mansouri I, Newborough M (1999) Dynamics of energy use in UK households: end-use monitoring of electric cookers. In: Energy efficiency and $\mathrm{CO}_{2}$ reduction: the dimension of the social challenge. Ademe, ECEEE 1999 summer study, Mandelier, France, 31/05/99

30. Ueno T, Inada R, Saeki O, Tsuji K (2005) Effectiveness of displaying energy consumption data in residential houses. Analysis on how the residents respond. In: ECEEE 2005 summer study, panel 6. dynamics of consumption, pp 1289-1299

31. Brandts J, Pezanis-Christou P, Schram A (2007) Competition with forward contracts: a laboratory analysis motivated by electricity market design. Econ J 118(525):192-214

32. Firth S, Lomas K, Wright A, Wall R (2008) Identifying trends in the use of domestic appliances from household electricity consumption measurements. Energy Build 40(5):926-936

33. Faruqui A, Arritt K, Sergici S (2017) The impact of advanced metering infrastructure on energy conservation: a case study of two utilities. Electr J 30(2017):56-63

34. Bertoldi P, Rezessy S, Oikonomou V (2013) Rewarding energy savings rather than energy efficiency: exploring the concept of a feed-in tariff for energy savings. Energy Policy 56:526-535

35. Boardman B (2006) Creating a virtuous circle for climate change with consumers, manufacturers and sufficiency. In: Energy efficiency in domestic appliances and lighting

36. Customer Engagement Committee (2014) Staff report on the work of the customer engagement committee, reforming the energy vision (REV) working group i: customer engagement
37. Filippini M, Hunt LC, Zorić J (2014) Impact of energy policy instruments on the estimated level of underlying energy efficiency in the EU residential sector. Energy Policy 69:73-81

38. Laes E, Mayeres I, Renders N, Valkering P, Verbeke S (2018) How do policies help to increase the uptake of carbon reduction measures in the EU residential sector? Evidence from recent studies. Renew Sustain Energy Rev 94:234-250

39. Faruqui A, Sergici S (2010) Household response to dynamic pricing of electricity: a survey of 15 experiments. J Regul Econ 38(2):193-225

40. Faruqui A, Sergici S (2017) Cody Warner. Arcturus 2.0: a metaanalysis of time-varying rates for electricity. Electr J 30:64-72

41. Frederiks ER, Stenner K, Hobman EV (2015) Household energy use: applying behavioural economics to understand consumer decision-making and behavior. Renew Sustain Energy Rev 41:1385-1394

42. Hahn R, Metcalfe R (2016) The impact of behavioral science experiments on energy policy. Economics of Energy \& Environmental Policy, International Association for Energy Economics, vol 0 (Number 2)

43. Lunn PD, Choisdealbha ÁN (2018) The case for laboratory experiments in behavioural public policy. Behav Public Policy 2:22-40

Publisher's Note Springer Nature remains neutral with regard to jurisdictional claims in published maps and institutional affiliations. 